\title{
Energy Dissipation Criteria for Surface Contact Damage Evaluation
}

\author{
Yong X. Gan \\ Department of Mechanical, Industrial and Manufacturing Engineering, \\ College of Engineering, University of Toledo,
}

USA

\section{Introduction}

This chapter presents the energy dissipation approach for analyzing surface contact damages in various materials, including composite materials. As known, surface contact is a very common phenomenon, which can be found in daily life and many scientific and engineering problems. The contact of different bodies can be modeled as indentation. Analysis of indentation and modeling of the deformation states of indented materials are often difficult because of the complexity of stress distributions within indentation zones. It is also very difficult to evaluate stress states in regions underneath an indented zone. Instrumental indentation has been performed on various materials including composite materials. Experimental studies on indention of coatings and brittle materials have been reported extensively, but the criterion for evaluating the extent of damage is not unified. Ductile materials deform relatively stable in indentation processes. While brittle materials are sensitive to compressive contact loadings in view of the formation of surface cracks. Therefore, it is difficult to find a unified stress or strain based damage criterion to characterize the damage evolution. Energy dissipation analysis may be more accurate to describe the deformation behavior of such materials. Specifically, under wedge indentation, the analysis should be investigated because the stress field has the singularity which limits the applicability of the strength criterion. In this chapter, the load-displacement relations with elastic-plastic responses of the materials associated with the indentation processes will be obtained to calculate the hysteresis energy. Lattice rotation measurement using electron backscatter diffraction (EBSD) technique will be performed in the region ahead of the indenter tip to measure the dimension of the contact damage zone (CDZ) and the results will be used to define the length scales in contact deformation. A unified criterion using the hysteresis energy normalized by the length scales will be established.

Damage evolution in composite materials is very sensitive to the interaction of reinforcements and matrices in interface regions. For example, the development of damage in glass particle and fiber reinforced epoxy composite materials is strongly influenced by the interface debonding conditions [1]. However, the exact effect of bonding conditions on the performance of particle filled composite materials is still not fully understood. Kawaguchi and Pearson [2] reported that strong matrix-particle adhesion may lower the fatigue crack propagation resistance. While the studies on $\mathrm{Si}_{3} \mathrm{~N}_{4}$ nanoparticle filled epoxy composites 
under sliding wear conditions showed that the strong interfacial adhesion between $\mathrm{Si}_{3} \mathrm{~N}_{4}$ nanoparticles and the matrix reduced the wear rate of the composites [3]. Damage in the form of debonding in coated fiber reinforced composites under tension-tension cyclic load was investigated [4]. The bi-interfacial debonding (fiber/coating and coating/matrix) behavior was analyzed using a double shear-lag model. Based on this model, the debond growth rate and strain energy were calculated by finite element method. Non-uniform damage of coating materials was accounted in the analysis. There exists two-interface coupling in debonding. It was found that the strength and thickness of coating materials are the major factors controlling the bi-interfacial crack growth. Numerical simulation of progressive damage evolution in fiber reinforced composites was performed to understand interface stress statistics and the fiber debonding paths development [5]. A meso cell including several hundred inclusions was used to account for the micro structure statistics of the composites. Both the local stress and effective elastic moduli of disordered fibrous composites were computed.

Micromechanics based approaches have been used for debonding damage analysis [6-10]. Cavallini, Bartolomeo, and Iacoviello [6] investigated the damage in three different ferriticpearlitic ductile cast irons with the main focus on graphite nodules debonding. Chan, Lee and Nicolella et al. [7] studied the near-tip fracture processes of nanocomposites under cyclic loads. It is found that particle bridging, debonding at the poles of particle/matrix interface, and crack deflection around the particles are the major micromechanics responses to cyclic loadings. Environmental conditions on the subcritical debond-growth rates were also examined [8]. Temperature and relative humidity are sensitive factors. Long term exposure to a moist environment resulted in the time-dependent decrease in adhesion between matrices and reinforcements. Three different interfacial damage models including the shear lag model, the linear degradation model and the modified power degradation model were used to describe the bond decay at steel/concrete interface [9]. The role of internal friction in resisting interfacial debonding was addressed. Micro-level damage in discontinuous fiber reinforced composites were found in the forms of fiber/matrix interfacial debonding and fiber failure [10]. The Weibull damage law was used to predict the microscopic damage behavior of composites with different fiber contents and orientations.

Crack initiation or small crack growth plays a critical role in interface debonding [11]. In small crack growth, plasticity-induced crack closure was observed, but the effect of crack closure in fatigue crack growth predictions was less than the estimation by the classical approaches [12]. In addition to crack closure, the shear deformation of matrix ahead of a small crack slows down the interfacial debonding rate [13]. Interface debonding controlled small crack growth behavior depends on the stress levels [14], and loading rate [15-16]. Microdebonding or subcritical debonding behavior is also dependent on surface chemistry [17] and temperature $[18,19]$. To evaluate the surface chemistry effect, subcritical debonding of thin polymer layers from inorganic dielectrics was studied using selected amino- and vinyl- functional silane adhesion promoters [17]. Due to the surface modification, the failure occurs not at the interface but in a region very close to the interface. The effect of temperature on debonding is especially significant in metal matrix composite materials [2034]. At elevated temperatures, thermomechanical fatigue accounts for the failure of these materials. Alternating plastic shearing of the interface takes place under combined mechanical and thermal stresses [18]. At low temperatures, metal matrices such as $\mathrm{Al}$ 
typically shows an initial hardening process, while at high temperatures, only cyclic softening is found [19].

Fatigue tests on reinforced titanium composites revealed various interface damage mechanisms [20-27]. Shear frictional sliding [20], interfacial debonding [21], fiber bridging [22], surface embrittlement [23], matrix ligament premature ductile shear [24], and crack deflection [25] are typical damage mechanisms observed. These damage mechanisms could occur simultaneously depending on loading modes, but debonding always exists and is considered as the major mechanism. A stress-based criterion for predicting the debonding behavior was proposed [22]. Rios, Rodopoulos and Yates [26] assessed the initial and final damage states caused by interface debonding and fiber bridging to determine the damage accumulation rates in $\mathrm{SiC}$ fiber reinforced titanium composite. Their method was used for damage tolerant fatigue design. Residual stiffness and the post-fatigued tensile strength as a function of microstructural damage were obtained through computer simulation, and the interfacial frictional stress and the critical crack length were also calculated [27]. Under combined thermal and mechanical fatigue loading, carbon fiber/Al and $\mathrm{SiC}$ fiber/Al composites were found to fail by a ratchetting mechanism, which is characterized by the progressive plastic deformation increasing with the number of cycles, even at stress levels far below the yield stress [28]. It is further found that the main phenomenon leading to composite failure is ratchetting at high load levels and interface degradation at low load levels.

Short crack growth behavior in steels containing different particle inclusions including $\mathrm{Al}_{2} \mathrm{O}_{3}, \mathrm{MnS}$ and $\mathrm{Ti}_{3} \mathrm{~N}_{4}$ was studied by finite element method [29]. Crack-tip displacements and energy release rates were taken as the driving forces. It was found that the energy release rate is the highest for the $\mathrm{Al}_{2} \mathrm{O}_{3}$ inclusion case with a short through thickness crack. $\mathrm{Li}$ and Ellyin [30] studied the fatigue damage and the localization in $\mathrm{Al}_{2} \mathrm{O}_{3}$ particulate reinforced aluminum composites. The primarily damage forms are particle debonding, fractured particles and matrix cracks. Mesoscale reinforcement defects, such as a clump of large particles were also found causing damage localization. These defects were assumed to be the reason for short crack initiation and extension. In Murtaza and Akid's work on steel [31], it is reported that debonding at the matrix/inclusion interface is the major mechanism for the formation of short cracks. Stress redistribution at interfaces in alumina/aluminum multilayered composites was investigated [32]. The effects of interfacial debonding or of plastic slip in the metal phase adjacent to strongly bonded interfaces were considered. The results of stress measured around the crack reveal that debonding is much more effective than slip in reducing the stress ahead of the crack. Interaction of short fatigue crack with different types of particles was studied. Stronger interaction of fatigue crack with Si particles, as compared to $\mathrm{SiC}$ particles, was observed in particle reinforced A356 casting alloy [33].

Modeling fatigue debonding have been performed by many researchers [34-39]. In Gradin and B ̈̈̈acklund's work [34], a unit cell model containing a steel bar and a co-centric epoxy cylinder was used to study the progressive de-bonding between the fiber and the matrix. Energy release rate was correlated to the interfacial debonding length. While in the work shown in [35-37], void formation and growth due to fatigue loading was characterized by the tensile stress at the interface. Three distinguishable debonding stages, two transient ones separated by a steady stage, were defined by Botsis and Zhao [38]. Stress intensity factor may be used to distinguish the steady and the transient stages because the total stress intensity factor was found to be approximately constant at the steady state. Debonding 
under different loading modes including mode I, mode II and mixed mode (I \& II) was studied by Dessureautt and Spelt [39]. It was observed that the debonding rate was the greatest under mixed-mode conditions.

In this chapter, the emphasis on mechanics analysis will be put on the damage initiation and propagation from the debonding of particle/matrix interface. Both macro- and micro-scale analysis will be performed. The macroscale approach based on continuum mechanics will be used to obtain the stress field in the elastic-plastic region within the matrix in front of the debonded particle. Treating the debonded region as a crack, stress intensity solutions can be obtained. In the plastic zone just ahead of the debonded particle, the microscale approach will be used to find the stress solutions. In the classical plasticity theory, the material property at the crack tip is considered to be isotropic and the maximum stress in the plastic zone is assumed to be the yield strength of the material. In this work, the particle-matrix interaction is modeled as surface contact and multiscale approaches are used in the modeling and experiments.

Why the particle-matrix interaction and the debonding in the interface region can be modeled as contact damage under indentation load? The rationale is evident by examining the damage zone. As shown in Figure 1, the particle inclusion is debonded from pearlitic steel matrix. Along the main crack propagation direction (marked as $x$-direction), two distinct slip regions are found. These regions are denoted as Region I and Region II. In each of these regions, persistent slip lines are found. Although there are also some other slip zones around the particle, the predominant slip activities that determine the main crack speed are from Region I and Region II. Therefore, with a simplified model, the slip in these two regions can be seen as generated by indentation. The hard particle is equivalent to an indenter.

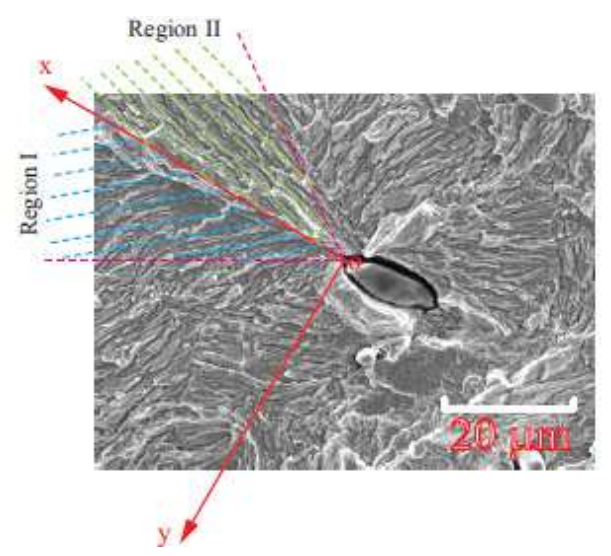

Fig. 1. Scanning electron microscopic image showing contact damage induced slip zones around a debonded particle. The main crack propagation is along $x$-axis.

\section{Surface contact damage model}

The first part of the modeling work is on the surface contact damage initiation using a microscale approach. Since the deformation state at the contact point is highly anisotropic, the deformation mechanism of single crystal plasticity is enforced in this stage. The 
deformation of the material in the indenter tip region due to the motion of dislocation on different slip systems will be described. Based on such a consideration, we assume that the stresses at the boundary between the elastoplastic region and the plastic zone propagate into the plastic zone. The magnitudes of the stress components are determined. The primary slip lines are assumed to be collinear with the dislocation motion directions. The second part of this section is specifically on the contact damage propagation. Once a short crack from the interface debonding starts growing, how to characterize the fatigue crack growth resistance becomes an important issue. A simulated crack (indenter penetration depth) is used to study the contact damage propagation kinetics. The specific energy of damage, a parameter which is used to characterize the resistance of the material to contact damage, is defined. The relationship between energy release rate and the specific energy of damage is established.

\subsection{Contact damage initiation stage: microscale approach}

It is assumed that the matrix is elastic-plastic so that in-plane slip is the prevailing plastic deformation mechanism. $S$ is the unit vector parallel to the slip direction. $N$ is the unit vector along the slip plan normal. To use indentation to simulate the debonding, the partial debonding and the fully debonded states, as shown in Figures 2(a) and 2(b), respectively, can be treated by the cases with indenter partially penetration and retreating. In order to find the stress solution, the debonded region is considered as a crack. A stress intensity approach is applied to find an approximate solution. Figures 2(c) shows both the global and the local coordinates for deriving the stress solutions in the slip regions.

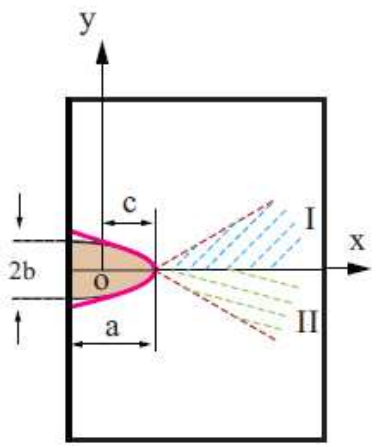

(a)

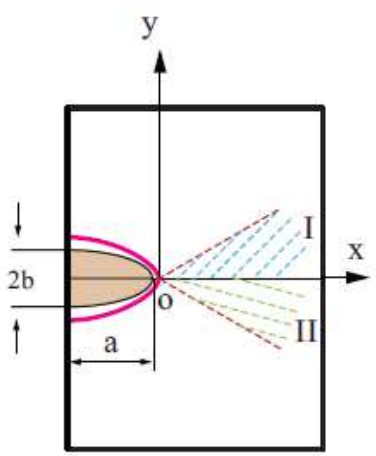

(b)

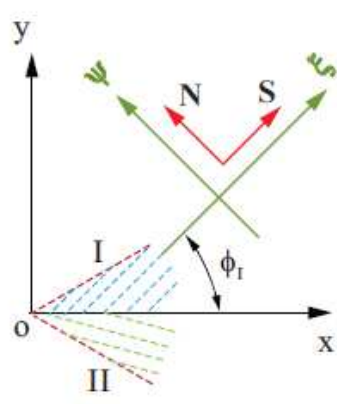

(c)

Fig. 2. Sketches for particle/matrix interface debonding analysis: (a) partial debonding, (b) complete debonding, (c) configuration of global, local coordinates related to the slip direction and slip plane normal vectors.

In a contact cycle, supposing that plane-strain conditions hold, the non-zero components of the stress field ahead of the particle are calculated by fracture mechanics as

$$
\sigma_{x x}=\frac{K_{I}}{\sqrt{2 \pi r}} \cos \left(\frac{\theta}{2}\right)\left[1-\sin \left(\frac{\theta}{2}\right) \sin \left(\frac{3 \theta}{2}\right)\right]
$$




$$
\begin{gathered}
\tau_{x z}=\tau_{z x}=\frac{K_{I}}{\sqrt{2 \pi r}} \cos \left(\frac{\theta}{2}\right) \sin \left(\frac{\theta}{2}\right) \sin \left(\frac{3 \theta}{2}\right) \\
\sigma_{z z}=\frac{K_{I}}{\sqrt{2 \pi r}} \cos \left(\frac{\theta}{2}\right)\left[1+\sin \left(\frac{\theta}{2}\right) \sin \left(\frac{3 \theta}{2}\right)\right] \\
\sigma_{y y}=\mu\left(\sigma_{x x}+\sigma_{z z}\right)
\end{gathered}
$$

where $K_{I}$ is the stress intensity factor related to the particle shape.

Other stress components are zeros, i.e. $\tau_{x y}=\tau_{y x}=\tau_{y z}=\tau_{z y}=0$. Assuming the material near the tip is fully plastic, the following yielding criterion holds

$$
N \Sigma S= \pm \tau_{i}
$$

where $\tau_{i}$ is the shear strength of the ith slip system, $\tau_{i}=\tau_{I}$ for Region I and $\tau_{i}=\tau_{I I}$ for Region II. $N$ is the surface normal of the slip plane, $S$ is a unit vector along the slip direction. If the dislocation motion is along positive $S$, the right hand side takes positive $\tau_{i}$, while in the case that the slip occurs along negative $S$, the negative sign is kept on the right hand side. $\Sigma$ is the stress tensor. The components of $N$ are $N_{x}, N_{y}$ and $N_{z}$ and $S$ has the components: $S_{x}, S_{y}$ and $S_{z}$. Since only the in-plane slip is considered in this work, the $z$-components for both $N$ and $S$ are zeros. Therefore, the yield condition is

$$
N_{x} \sigma_{x x} S_{x}+N_{y} \sigma_{y y} S_{y}= \pm \tau_{i}
$$

where $S_{x}=\cos \left(\varphi_{i}\right), S_{y}=\sin \left(\varphi_{i}\right), N_{x}=-\sin \left(\varphi_{i}\right), N_{y}=\cos \left(\varphi_{i}\right), \varphi_{i}=\varphi_{I}$ for Region $I$ and $\varphi_{i}=\varphi_{I I}$ for Region II. Substituting these relations into Eq. (3) yields

$$
-\frac{\sigma_{x x}-\sigma_{y y}}{2} \sin \left(2 \varphi_{i}\right)= \pm \tau_{i}
$$

Eq. (4) provides the yield function related to the slip angle and the stress field when the material is in a fully-plastic state. For the partial debonding case, along the radial line $\theta=0$, the in-plane stresses are

$$
\begin{gathered}
\sigma_{x x}=\frac{K_{I}}{\sqrt{2 \pi r^{*}}} \\
\tau_{x y}=0 \\
\sigma_{y y}= \pm \frac{2 \tau_{i}}{\sin \left(2 \varphi_{i}\right)}+\sigma_{x x}
\end{gathered}
$$

where $r^{*}$ is the distance from the origin to an arbitrary point on the $\theta=0$ radial line, and $K_{I}=\frac{1.12}{\pi} \sqrt{\pi(a-c) \sigma_{\infty}}$. 
Once the stress field along the radial line $\theta=0$ is obtained, it is straightforward to find the stress state within the slip region. One of the ways is to follow the slip line analysis [40] to solve the stress components in Region I and Region II.

\subsection{Contact damage propagation stage: macroscale approach}

In this part, evaluation of the contact damage propagation behavior based on experimentally determined irreversible work and energy dissipation is presented. The energy dissipated into damage formation is considered as the indentation penetration driving force. A materials parameter, the specific energy of damage is used as the contact damage tolerance criterion as previously introduced for some materials in [41-46]. Correlation between the contact damage tolerance and the microstructure of the material is made.

Considering indenter penetration region and its surrounding damage zone in the material as a thermodynamic entity, the following relationship can be obtained based on entropy and energy balance considerations.

$$
T \dot{S}=\left(J^{*}-a \gamma\right) \frac{d a}{d N}+D
$$

where $T$ is the ambient temperature and $\dot{S}$ is the rate of change of the entropy of the system comprising the indenter penetration region and the surrounding damage zone. $J^{*}$ is the energy release rate. $\gamma$ is the specific damage of energy. $a$ is the nominal indenter penetration depth or developed contact length between the indenter and the indented material. $\mathrm{d} a / \mathrm{d} N$ is the indenter penetration speed. $N$ is the number of indentation cycles. $D$ is the rate of energy dissipation into contact damage formation associated with the damage zone evolution.

At minimum entropy, $T \dot{S}=0$. Eq. (6) can be rearranged as

$$
\frac{d a}{d N}=\frac{D}{a \gamma-J^{*}}
$$

Under force control indentation conditions, the energy release rate $J^{*}$ can be evaluated by

$$
\frac{d a}{d N}=\frac{1}{B} \frac{\partial P}{\partial a}
$$

where $P$ is the potential energy (area above the unloading curve) at the indenter penetration depth $a$, and $B$ is the specimen thickness. The cyclic rate of energy dissipation, $D$ associated with contact damage zone evolution can be evaluated by the difference between the hysteresis energy related to indentation and the hysteresis energy dissipated into the bulk of the material. It can be expressed as:

$$
D=\frac{H_{n}}{B}
$$

where $H_{n}$ is the hysteresis energy. Rearranging Eq. (7) yields 


$$
\frac{J^{*}}{a}=\gamma-\frac{D}{a\left(\frac{d a}{d N}\right)}
$$

The quantities $J^{*}, \mathrm{~d} a / \mathrm{d} N$, and $a$, can be obtained from indentation experiments. The relationship expressed in Eq. (10) can be plotted in a two dimensional domain, directly giving the value of the specific energy of damage, $\gamma$, which is the intercept of the straight line. $\gamma$ can be used as a material property related parameter. By examining Eq. (10), as the contact damage propagates, the energy release rate increases, thus the change of the left term $J^{*} / a$ can be leveled by both the increasing of $J^{*}$ and the indentation penetration depth, $a$. The variation of the term in the right side of Eq. (10), $D /(a(d a / d N)]$, depends on several factors. These are the indentation depth, $a$, the indentation speed, $\mathrm{d} a / \mathrm{d} N$ and $D$, the cyclic rate of energy associated with the damage formation. The indentation speed changes with the indentation depth. From energy balance analysis, it is clear that the value of $D$ changes with the indentation depth, $a$. Thus, the variation of $D$ is well balanced by the change in both $a$ and $\mathrm{d} a / \mathrm{d} N$. Thus, on the $J^{*} / a$ vs $D /[a(d a / d N)]$ plot, a straight line which is almost parallel to the $D / a(d a / d N)]$ axis can be obtained.

\section{Experimental}

The materials used include two types. One type is copper for indentation penetration zone measurement. The other one is a medium carbon steel with inclusions for simulated surface damage propagation analysis. A hardened tool carbon steel by heat treatment was used to make the wedge indenter. The indentation configuration is shown in Figure 3. The indenter has a $90^{\circ}$ apex angle. The indentation process was conducted under cyclic loading conditions. During indentation, the load and the displacement was recorded by an Xplorer GLX data acquisition unit. These data can be used to plot and show the relation of the indentation load v.s. the nominal indenter penetration depth.

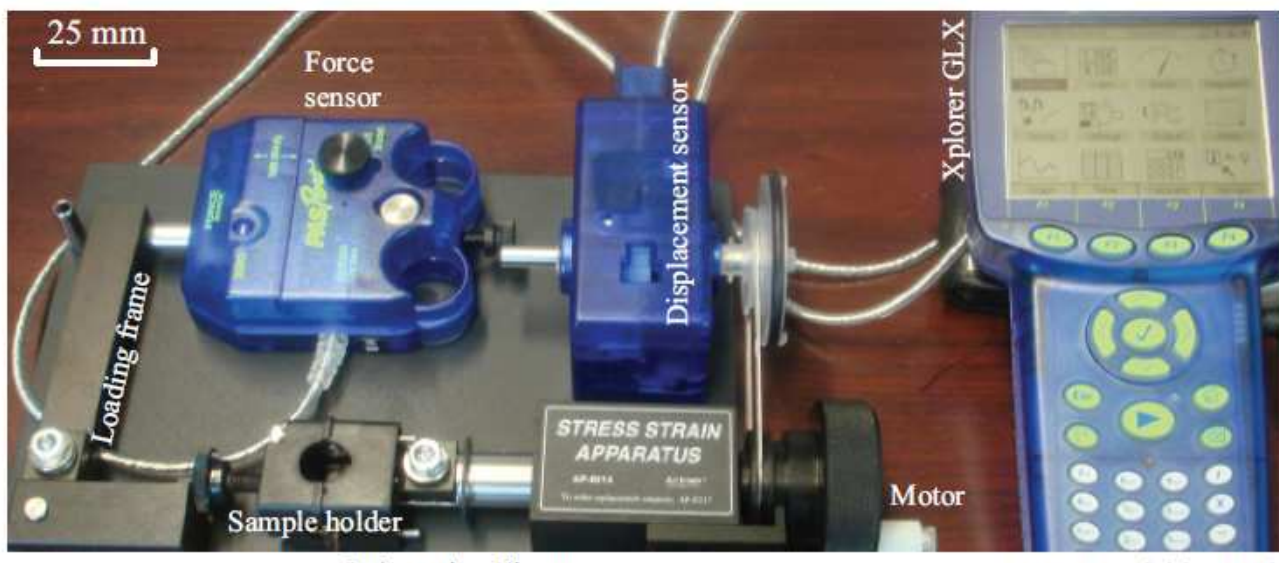

Indentation Fixture

Data Acquisition Unit

Fig. 3. Indentation set-up for performing simulated surface contact damage tests. 
There exists difficulty in measuring the actual damage zone size by direct visual observation. We examined indented copper crystal using scanning electron microscopy (SEM) and measured the damage zone size. The copper polycrystal was etched in warm $\mathrm{HCl} / \mathrm{SnCl}_{4}$ solution. Further investigation of the damage zone using electron backscattering diffraction (EBSD) technique to reveal the contact damage zone in single crystal copper was also performed.

\section{Results and discussion}

The indentation cyclic load vs time is shown in Figure 4(a). Time-dependent indentation penetration depth was recorded and shown in Figure 4(b). The relation of the indentation load v.s. the indenter penetration depth at a typical cycle is shown in Figure 4(c). From the load-displacement curves, we can calculate the potential energy and the hysteresis energy associated with the contact damage processes as schematically shown in Figure 4(d). The indentation penetration depth, $a$, versus the number of indentation cycles, $N$, for three steels was plotted. The slope of the $a$ versus $N$ curves was used to calculate $\mathrm{d} a / \mathrm{d} N$, and establish the relationship of indentation speed, $\mathrm{d} a / \mathrm{d} N$, and indentation depth, $a$.
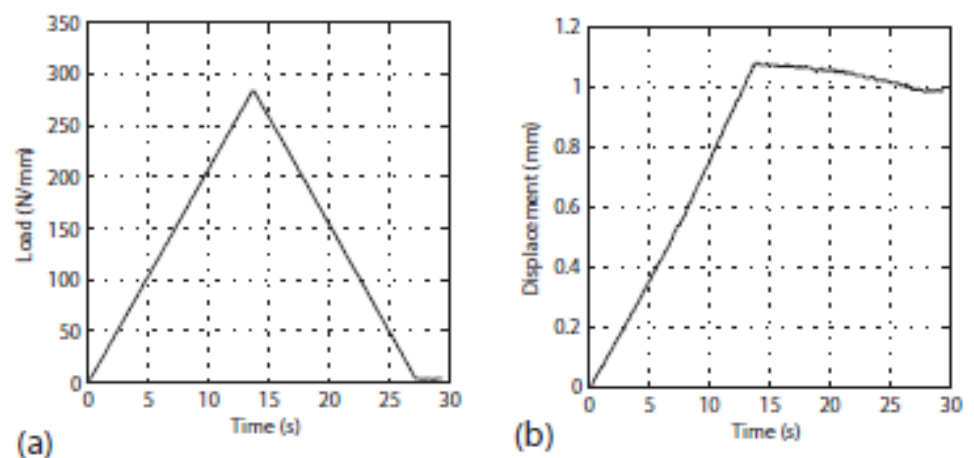

(a)
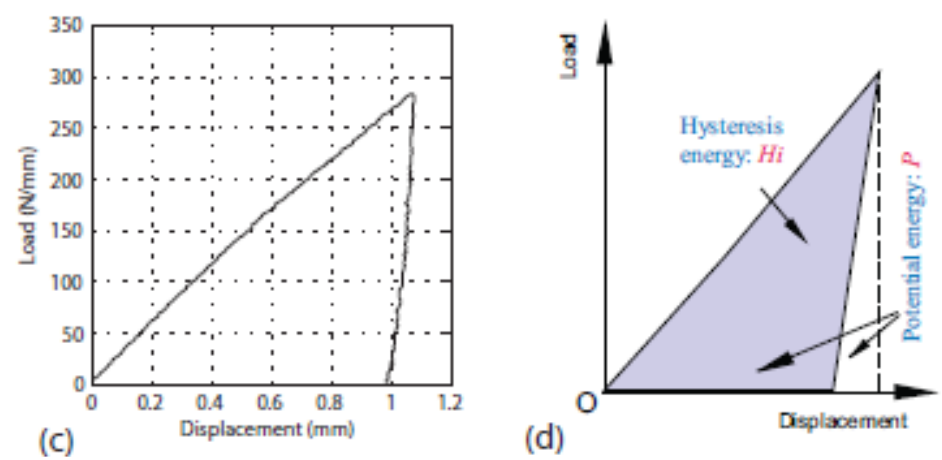

Fig. 4. Calculating energy dissipation terms from indentation test data: (a) cyclic loading profile, (b) time-dependent displacement, (c) load-displacement relationship, (d) illustration showing how to determine the potential energy and hysteresis energy. 
The potential energy, $P$, was calculated from the loading and unloading curves recorded at intervals of number of cycles as the area above the unloading curve (see Figure $4(\mathrm{~d})$ ). On this basis, the relationship between the potential energy and the indentation depth, $a$, can be established. The relationship between $P$ and $a$ is used to determine the energy release rate, $J^{*}$, using Eq. (8). The hysteresis energy at each indentation cycle $H_{n}$ is determined from the area of the hysteresis loop recorded as schematically shown in Figure 4(d). Based on the value of hysteresis energy and the relationship between $a$ versus $N$, the quantity of $D$, the cyclic rate of energy dissipation into contact damage zone evolution is determined using Eq. (9).

Figure 5 shows the fatigue crack growth behavior of three medium carbon steels (named as materials $A, B$ and $C$ ) due to the interface debonding of particle inclusions and the pearlite matrix. The carbon content of the three steels is $0.77 \%$ in weight. However, the heat treatment conditions are not the same, which affected their fatigue property. Steel $A$ was heat treated at the highest cooling rate. $B$ has a much lower cooling rate than $A$, while $C$ has an even lower cooling rate, but close to that of $B$. Tension-tension fatigue tests with cyclic loading ratio of $R=0: 1$ were performed. It is found that the energy release rate and the cyclic energy dissipation rate change constantly for each of the materials during the fatigue crack growth. We also found that the critical value of energy release rate is very difficult to determine as shown in Figure 5(a), the energy release rate, $J^{*}$, versus the crack length for the three steels. The increase of the crack length, $a$, causes the increase of the values of $J^{*}$ for the three steels. Therefore, the energy release rate can not be considered as a materials parameter for comparing the fatigue damage tolerance of different materials because a unified value for each material can not be found.

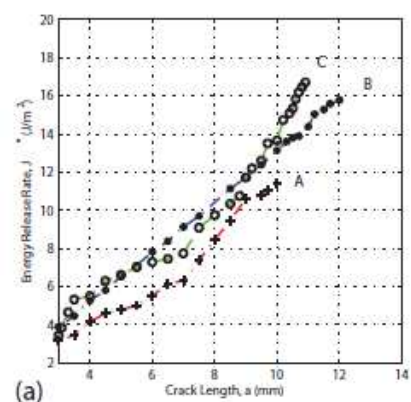

(a)

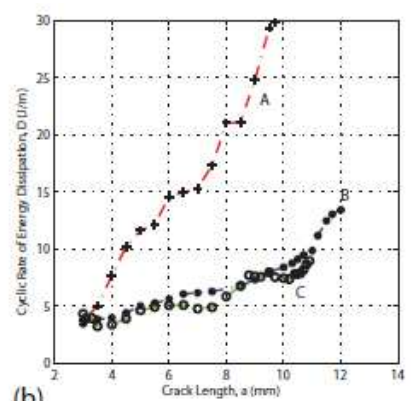

(b)

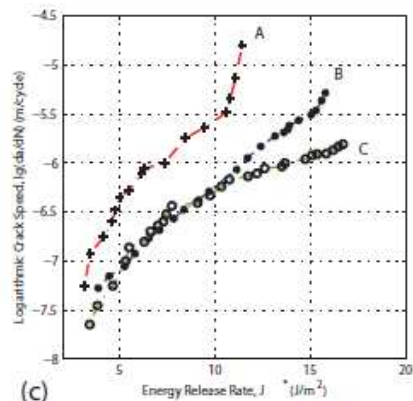

(c)

Fig. 5. The fatigue crack propagation data of three medium carbon steels: (a) the energy release rate, $J^{*}$, versus the crack length, $a,(b)$ the cyclic rate of energy dissipation, $D$, versus the crack length, $a$, (c) crack speed versus the energy release rate.

The irreversible energy dissipation during fatigue damage of the three steels was also calculated. Based on the measured hysteresis energy for both notched and unnotched specimens and the relationship between crack length $a$ versus fatigue cycle $N$, the quantity of $D$, the cyclic rate of energy dissipation into damage zone evolution was determined. The relationships of $D$ and the crack length, $a$, for the steels, are shown in Figure 5(b). Material $A$ displayed much higher value of the cyclic rate of energy dissipation into the active zone evolution. The other two steels, $B$ and $C$ demonstrated very similar behavior. For all of the three steels, it is evident that with the increase in crack length, the values of $D$ increase. 
The fatigue crack propagation speed versus the energy release rate for the three steels is shown in Figure 5(c). Steel $A$ displayed the highest crack growth speed in the entire energy release rate range. In most part of the energy release rate range, for say, $J^{*}$ less than $12 \mathrm{~kJ} / \mathrm{m}^{2}$, steel $B$ and $C$ have the crack speed very close to each other. In the energy release rate range of higher than $12 \mathrm{~kJ} / \mathrm{m}^{2}, B$ has higher crack speed than $C$. It can also be seen from Figure 5(c) that the three curves display the similar two-stage crack growth behavior which are corresponding to the stable crack growth stage and the unstable crack growth stage of the specimens from the three steels. A threshold stage was observed only in the pre-crack initiation stage for $A$ and $B$. But it extended to the beginning of the stable crack propagation stage for the specimens from $C$. In the stable crack propagation stage, the decreased acceleration in crack speed is an indicative of material damage within the area in front of the crack tip associated with fatigue crack propagation.

The damage tolerance is evaluated by the specific energy of damage $\gamma$. The parameters $\gamma$ was calculated using the experimental data generated from fatigue tests including $a, \mathrm{~d} a / \mathrm{d} N$, $J^{*}$, and $D$. A plot of $J^{*} / a$ versus $\left.D / a(d a / d N)\right]$ can be generated for each material. Based on the results of the three steels, $A, B$ and $C$, we generated Figure 6 . Three straight lines which are almost parallel to the horizontal axis were obtained for the three steels. The intercepts of the three lines give the values of $\gamma$ for each layer. From the results shown in Figure 6 , the value of $\gamma$, being a material property related parameter, is suitable for characterizing the fatigue damage tolerance.

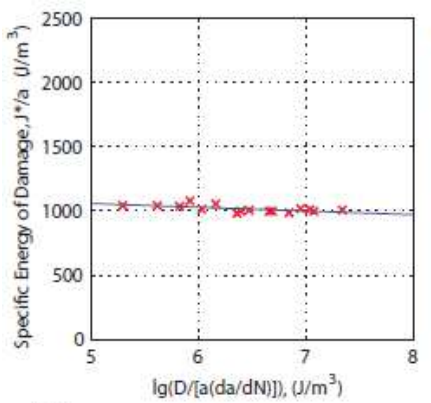

(a)

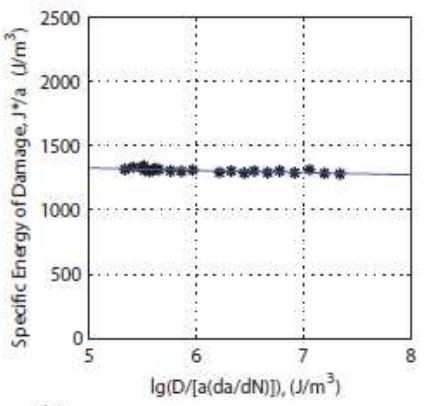

(b)

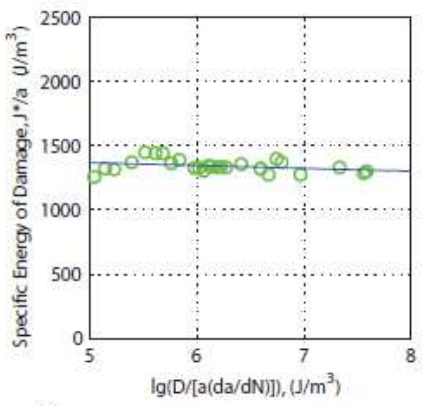

(c)

Fig. 6. Plot for determining the specific energy of damage, $\gamma$, of the three medium carbon steels under different heat treatment conditions: (a) steel A, (b) steel B, (c) steel C.

Due to the microstructure change with heat treatment conditions, the specific energy of damage for each of the steels is different. Steel $A$ with hardening treatment, has the lowest $\gamma$, while $C$ shows the highest $\gamma$ due to tempering treatment. The specific energy of damage of steel $B$, heat treated at very low air cooling rate, is close to that of $C$. Since $\gamma$ is almost a constant for each material tested, it can be taken as a parameter characteristic of the fatigue damage tolerance for evaluating the resistance to fatigue crack growth.

Although the indentation penetration depth is fairly straightforward to be recorded, it is challenge to measure the actual damage zone size. Figure $7(\mathrm{a})$ is the scanning electron microscopic (SEM) image of the copper polycrystal after etching in warm $\mathrm{HCl} / \mathrm{SnCl}_{4}$ solution. It can be seen that the grain boundaries are etched away by the solution. The precision polishing helped to expose the etching pits and islands on the surface of the 
specimen. These features come from the selectively dissolving of materials located near the ends of the dislocation lines. However, the indented damage zone is still unclear.

Further investigation of the damage zone using electron backscattering diffraction (EBSD) technique reveals different features within the contact damage zone. For example, the band contract map, Figure 7(b), provides the features of subgrain formation and recrystallization of the single crystal grain under wedge indentation after annealing. Since the intensity of the backscatter electrons changes from grain to grain, the grain boundary can be revealed by the band contrast change. Thus, it is possible to identify the microstructure in the area close to the indentation tip. By this method, the subgrain formation due to severe contact damage and plastic deformation can be revealed. The average size of the subgrains shown in Figure 7(b) is about 10 to $15 \mu \mathrm{m}$. It is also found there is an elliptical region in front of the indentation tip, which corresponds to the strain hardened elastic-plastic zone. Deeper into the indentation region, it is the fully plastic deformation zone, as shown by the in-plane lattice rotation map in Figure 7(c). Such EBSD results will provide us the insight into how to determine the size of the damage zone. For example the conservative measurement will give us the size of the damage zone the same as the indenter penetration zone (IPZ) as shown by the elliptical region in Figure 7(b). A more accurate measurement should account for the extended plastic region as shown in Figure 7(c). The distance from point $A$ to point $C$ or $E$ instead of just from point $O$ to $A$ should be considered as the damage zone size, which is about 5 times larger than the indenter penetration zone (IPZ). This EBSD measurement results were used to correct the damage tolerance calculation by adding the contact damage zone size to the indenter penetration depth or crack length, $a$. Consequently, the indenter penetration speed $\mathrm{d} a / \mathrm{d} N$ was modified as the damage zone expansion speed.

(a)

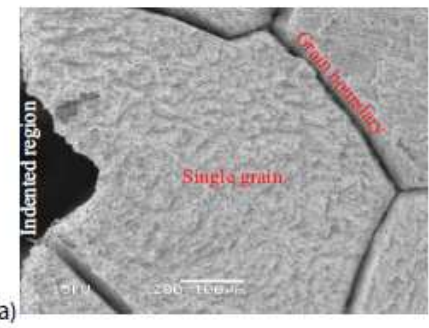

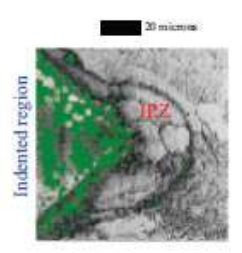

(b)

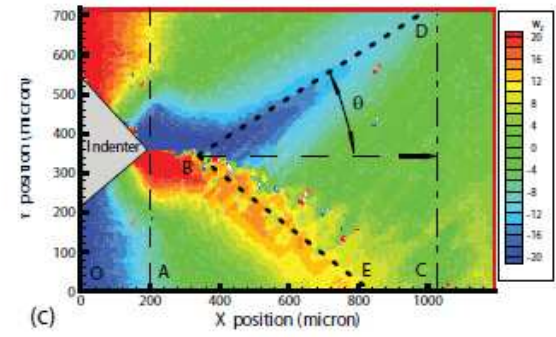

(c)

Fig. 7. Measuring the size of indentation contact damage zone via electron microscopy: (a) scanning electron microscopic measurement, (b) band contrast map of the indentation penetration zone obtained by electron backscatter diffraction (EBSD) measurement, (c) in plane lattice rotation map generated by electron backscatter diffraction (EBSD)

measurement.

\section{Conclusions}

The energy dissipation approach is applicable for analyzing surface contact damages in various materials, including composite materials. The contact of different bodies can be modeled as indentation. Analysis of indentation and modeling of the deformation states of indented materials at different scales are performed. The stress distributions within indentation zones are described by fracture mechanics, and single crystal plasticity solutions 
to the stress states in regions underneath the indented zone are obtained. Instrumental indentation performed on copper materials with different grain sizes reveals both the indentation zone and damage zone. The reason for choosing copper is the high ductility of copper which allows deformation develops in a stable way during the indentation processes.

Based on the experimental studies of fatigue crack growth on three steels, the criterion for evaluating the extent of damage is identified. Although it is difficult to find a unified stress or strain based damage criterion to characterize the damage evolution, energy dissipation analysis provides a more accurate way to describe the deformation behavior of the materials. Under wedge indentation, the analysis shows advantage because the stress field has the singularity which limits the applicability of the strength criterion. The loaddisplacement relations with elastic-plastic responses of the materials associated with the indentation processes were obtained. The hysteresis energy was also determined. Lattice rotation measurement using electron backscatter diffraction (EBSD) technique in the region ahead of the indenter tip is an effective way to measure the dimension of the contact damage zone (CDZ) and the results can be used to define the length scales during contact deformation. A unified criterion using the hysteresis energy normalized by the length scales has been established. The above mentioned indentation tests in this work caused deformation of significant amount of materials. For further studies, comparison of deep indentation and nanoindentation should be performed.

\section{References}

[1] Kawaguchi, T., \& Pearson, R.A. (2004). The moisture effect on the fatigue crack growth of glass particle and fiber reinforced epoxies with strong and weak bonding conditions Part 2: A microscopic study on toughening mechanism, Composites Science and Technology. Vol. (64): 1991-2007

[2] Kawaguchi, T. \& Pearson, R.A. (2004). The moisture effect on the fatigue crack growth of glass particle and fiber reinforced epoxies with strong and weak bonding conditions Part 1: Macroscopic fatigue crack propagation behavior, Composites Science and Technology. Vol. (64): 1981-1989

[3] Shi, G., Zhang, M.Q., Rong, M.Z., Wetzel, B. \& Friedrich, K. (2003). Friction and wear of low nanometer $\mathrm{Si}_{3} \mathrm{~N}_{4}$ filled epoxy composites, Wear. Vol.(254): 784-796

[4] Zhang, R. \& Shi, Z. (2008). Bi-interfacial debonding of coated fiber reinforced composites under fatigue load, International Journal of Fatigue. Vol.(30): 1074-1079

[5] Kushch, V.I., Shmegera, S.V. \& Mishnaevsky, L. (2008). Meso cell model of fiber reinforced composite: Interface stress statistics and debonding paths, International Journal of Solids and Structure. Vol.(45): 2758-2784

[6] Cavallini, M., Di Bartolomeo, O.D. \& Iacoviello, F. (2008). Fatigue crack propagation damaging micromechanisms in ductile cast irons, Engineering Fracture Mechanics. Vol.(75): 694-704

[7] Chan, K.S., Lee, Y.D., Nicolella, D.P., Furman, B.R., Wellinghoff, S. \& Rawls, R. (2007). Improving fracture toughness of dental nanocomposites by interface engineering and micromechanics, Engineering Fracture Mechanics. Vol.(74):1857-1871

[8] Sharratt, B.M., Wang, L.C. \& Dauskardt, R.H. (2007). Anomalous debonding behavior of a polymer/inorganic interface, Acta Materialia. Vol.(55): 3601-3609 
[9] Shi, Z., Cui, C. \& Zhou, L. (2006). Bond decay at barconcrete interface under variable fatigue loads, European Journal of Mechanics. Vol.(25): 808-818

[10] Kabir, M.R., Lutz, W., Zhu, K. \& Schmauder, S. (2006). Fatigue modeling of short fiber reinforced composites with ductile matrix under cyclic loading, Composite Materials Science. Vol. (36): 361-366

[11] Okazaki, M. \& Yamano, H. (2005). Mechanisms and mechanics of early growth of debonding crack in an APSed Ni-base superalloy TBCs under cyclic load, International Journal of Fatigue. Vol.(27):1613-1622

[12] Jiang, Y., Feng, M. \& Ding, F. (2005). A reexamination of plasticity-induced crack closure in fatigue crack propagation, International Journal of Plasticity. Vol.(21): 17201740

[13] Shi, Z., Chen, Y. \& Zhou, L. (2005). Micromechanical damage modeling of fiber/matrix interface under cyclic loading, Composites Science and Technology. Vol.(65): 1203-1210

[14] Chen, Z. Z. \& Tokaji, K. (2004). Effects of particle size on fatigue crack initiation and small crack growth in SiC particulate-reinforced aluminum alloy composites, Materials Letters. Vol.(58): 2314-2321.

[15] Foley, M.E., Obaid, A.A., Huang, X., Tanoglu, M., Bogetti, T.A., McKnight, S.H. \& Gillespie, J.W. (2002). Fiber/matrix interphase characterization using the dynamic interphase loading apparatus, Composites A: Applied Science and Manufacturing. Vol.(33): 1345-1348

[16] Hong, H.U., Rho, B.S. \& Nam, S.W. (2002). A study on the crack initiation and growth from delta-ferrite/gamma phase interface under continuous fatigue and creepfatigue conditions in type 304L stainless steels, International Journal of Fatigue. Vol.(24): 1063-1070

[17] Snodgrass, J.M., Pantelidis, D., Jenkins, M.L., Bravman, J.C. \& Dauskardt, R.H. (2002). Subcritical debonding of polymer/silica interfaces under monotonic and cyclic loading, Acta Materialia. Vol.(50): 2395-2411

[18] Zhang, J., Wu, J. \& Liu, S. (2002). Cyclically thermomechanical plasticity analysis for a broken fiber in ductile matrix composites using shear lag model, Composites Science and Technology. Vol.(62): 641-654

[19] Biermann, H., Kemnitzer, M. \& Hartmann, O. (2001). On the temperature dependence of the fatigue and damage behaviour of a particulate-reinforced metal-matrix composite, Materials Science and Engineering A. Vol.(319-321): 671-674

[20] Tanaka, Y., Kagawa, Y., Liu, Y.F. \& Masuda, C. (2001). Interface damage mechanism during high temperature fatigue test in $\mathrm{SiC}$ fiber-reinforced $\mathrm{Ti}$ alloy matrix composite, Materials Science and Engineering A. Vol.(314): 110-117

[21] Rodopoulos, C. A., Yates, J.R. \& Rios, E.R., Micro-mechanical modeling of fatigue damage in titanium metal matrix composites, Theoretical and Applied Fracture Mechanics. Vol.(35): 59-67.

[22] Warrier, S.G., Maruyama, B., Majumdar, B.S. \& Miracle, D.B. (1999). Behavior of several interfaces during fatigue crack growth in $\mathrm{SiC} / \mathrm{Ti}-6 \mathrm{Al}-4 \mathrm{~V}$ composites, Materials Science and Engineering A. Vol.(259): 189-200

[23] Foulk, J.W., Allen, D.H. \& Helms, K.L.E. (1998). A model for predicting the damage and environmental degradation dependent life of SCS-6/Ti metal matrix composite, Mechanics of Materials. Vol.(29): 53-68 
[24] Doel, T.J.A., Cardona, D.C. \& Bowen, P. (1998). Fatigue crack growth in selectively reinforced titanium metal matrix composites, International Journal of Fatigue. Vol.(20): 35-50

[25] Warrier, S.G., Majumdar, B.S. \& Miracle, D.B. (1997). Interface effects on crack deflection and bridging during fatigue crack growth of titanium matrix composites, Acta Materialia. Vol.(45): 4969-4980

[26] Rios, E.R., Rodopoulos, C.A. \& Yates, J.R. (1997). Damage tolerant fatigue design in metal matrix composites, International Journal of Fatigue. Vol.(19) : 379-387

[27] Wang, P.C., Jeng, S.M., Yang, J.M. \& Russ, S.M. (1996). Fatigue damage evolution and property degradation of a SCS-6/Ti-22Al-23Nb "orthorhombic" titanium aluminide composite, Acta Materialia. Vol.(44): 3141-3156

[28] Ghorbel, E. (1997). Interface degradation in metal-matrix composites under cyclic thermomechanical loading, Composites Science and Technology. Vol.(57): 1045-1056

[29] Melander, A. (1997). A Finite element study of short cracks with different inclusion types under rolling contact fatigue load, International Journal of Fatigue. Vol.(19): 1324

[30] Li, C. \& Ellyin, F. (1996). Fatigue damage and its localization in particulate metal matrix composites, Matererials Science and Engineering A. Vol.(214): 115-121

[31] Murtaza, G. \& Akid, R. (1995). Modeling short fatigue-crack growth in a heat-treated low-alloy steel, International Journal of Fatigue. Vol.(17): 207-214

[32] Shaw, M.C., Marshall, D.B., Dalgleish, B.J., Dadkhah, M.S., He, M.Y. \& Evans, A.G. (1994). Fatigue-crack growth and stress redistribution at interfaces, Acta Metallurgica et Materialia. Vol.(42): 4091-4099

[33] Wang, Z. \& Zhang, R. J. (1994). Microscopic characteristics of fatigue-crack propagation in aluminum alloy based particulate reinforced metal matrix composites, Acta Metallurgica et Materialia. Vol.(42): 1433-1445

[34] Gradin, P.A. \& BÄacklund, J. (1981). Fatigue debonding in fibrous composites, International Journal of Adhesion and Adhesives. Vol.(1): 154-158

[35] Horst, J.J., Salienko, N.V., Spoormaker, J.L. (1998) Fibre-matrix debonding stress analysis for short fibre-reinforced materials with matrix plasticity, finite element modelling and experimental verification, Composites A: Applied Science and Manufacturing. Vol.(29): 525-531

[36] Horst, J.J. \& Spoormaker, J.L. (1996). Mechanisms of fatigue in short glass fiber reinforced polyamide 6, Polymer Engineering Science. Vol.(36): 2718-2726

[37] Horst, J.J. \& Spoormaker, J.L. (1997). Fatigue fracture mechanisms and fractography of short glass fiber reinforced polyamide 6, Journal of Materials Science. Vol.(32): 36413651

[38] Botsis, J. \& Zhao, D. (1997). Fatigue fracture process in a model composite, Composites A: Applied Science and Manufacturing. Vol.(28): 657-666

[39] Dessureautt, M. \& Spelt, J.K. (1997). Observations of fatigue crack initiation and propagation in an epoxy adhesive, International Journal of Adhension and Adnesives. Vol.(17): 183-195

[40] Kysar, J.W., Gan, Y.X. \& Mendez-Arzuza, G. (2005). Cylindrical void in a rigid-ideally plastic single crystal Part I: Anisotropic slip line theory solution for face-centered cubic crystals, International Journal of Plasticity. Vol.(21): 1481-1520 
[41] Aglan, H., Gan, Y.X., Chu, F. \& Zhong, W.H. (2003). Fatigue damage analysis of particulate and fiber filled PTFEs based on energy expended on damage formation, Journal of Reinforced Plastics and Composites. Vol.(22): 339-360

[42] Aglan, H. \& Gan, Y.X. (2001). Fatigue crack growth analysis of a premium rail steel, Journal of Materials Science. Vol.(36): 389-397

[43] Aglan, H.A., Gan, Y.X., Chin, B.A. \& Grossbeck, M.L. (2000). Effect of Composition on the fatigue failure behavior of vanadium alloys, Journal of Nuclear Materials. Vol.(278): 186-194

[44] Aglan, H., Gan, Y.X., Chin, B.A. \& Grossbeck, M.L. (1999). Fatigue failure analysis of V4Ti-4Cr alloy, Journal of Nuclear Materials. Vol.(237): 192-202

[45] Gan, Y., El-Hadik, M., Aglan, H., Faughnan, P. \& Bryan, C. (1999) Fatigue crack growth analysis of PCTFE, Journal of Elastomers and Plastics. Vol.(34): 96-129

[46] Aglan, H., Gan, Y., El-Hadik, M., Faughnan, P. \& Bryan, C. (1999). Evaluation of fatigue fracture resistance of unfilled and filled PTFE materials, Journal of Materials Science. Vol.(34): 83-97 


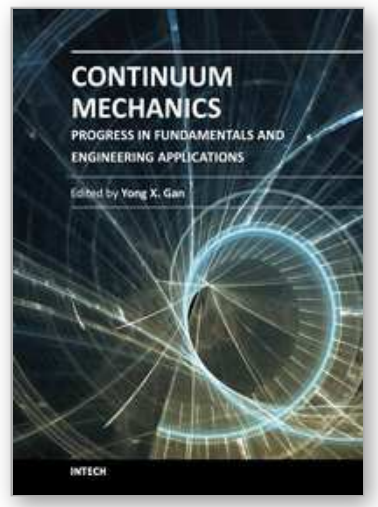

\author{
Continuum Mechanics - Progress in Fundamentals and \\ Engineering Applications \\ Edited by Dr. Yong Gan
}

ISBN 978-953-51-0447-6

Hard cover, 158 pages

Publisher InTech

Published online 28, March, 2012

Published in print edition March, 2012

Continuum Mechanics is the foundation for Applied Mechanics. There are numerous books on Continuum Mechanics with the main focus on the macroscale mechanical behavior of materials. Unlike classical Continuum Mechanics books, this book summarizes the advances of Continuum Mechanics in several defined areas. Emphasis is placed on the application aspect. The applications described in the book cover energy materials and systems (fuel cell materials and electrodes), materials removal, and mechanical response/deformation of structural components including plates, pipelines etc. Researchers from different fields should be benefited from reading the mechanics approached to real engineering problems.

\title{
How to reference
}

In order to correctly reference this scholarly work, feel free to copy and paste the following:

Yong X. Gan (2012). Energy Dissipation Criteria for Surface Contact Damage Evaluation, Continuum Mechanics - Progress in Fundamentals and Engineering Applications, Dr. Yong Gan (Ed.), ISBN: 978-953-510447-6, InTech, Available from: http://www.intechopen.com/books/continuum-mechanics-progress-infundamentals-and-engineering-applications/energy-dissipation-criteria-for-surface-contact-damage-evaluation

\section{INTECH}

open science | open minds

\section{InTech Europe}

University Campus STeP Ri

Slavka Krautzeka 83/A

51000 Rijeka, Croatia

Phone: +385 (51) 770447

Fax: +385 (51) 686166

www.intechopen.com

\section{InTech China}

Unit 405, Office Block, Hotel Equatorial Shanghai

No.65, Yan An Road (West), Shanghai, 200040, China

中国上海市延安西路65号上海国际贵都大饭店办公楼405单元

Phone: +86-21-62489820

Fax: +86-21-62489821 
(C) 2012 The Author(s). Licensee IntechOpen. This is an open access article distributed under the terms of the Creative Commons Attribution 3.0 License, which permits unrestricted use, distribution, and reproduction in any medium, provided the original work is properly cited. 